
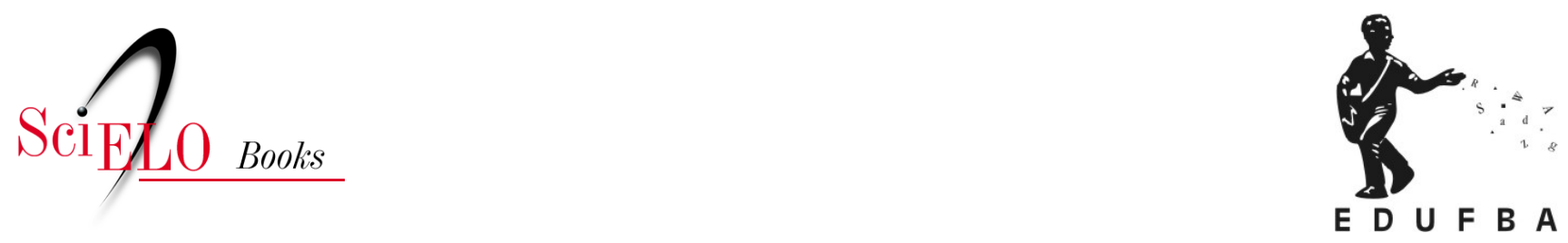

\title{
Prefácio \\ A luta contra a aids: a originalidade do caso brasileiro
}

\author{
Patrice Pinell
}

\section{SciELO Books / SciELO Livros / SciELO Libros}

PINELL, P. Prefácio - A luta contra a aids: a originalidade do caso brasileiro. In: BARROS, S.G. Política Nacional de Aids: construção da resposta governamental à epidemia HIV/aids no Brasil [online]. Salvador: EDUFBA, 2018, pp. 9-14. ISBN 978-85-232-2030-3.

https://doi.org/10.7476/9788523220303.0001.

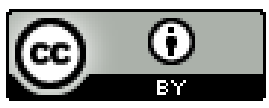

All the contents of this work, except where otherwise noted, is licensed under a Creative Commons Attribution 4.0 International license.

Todo o conteúdo deste trabalho, exceto quando houver ressalva, é publicado sob a licença Creative Commons Atribição 4.0. 


\section{Prefácio}

\section{A luta contra a aids: a originalidade do caso brasileiro}

Nesta obra, Sandra Garrido propõe uma análise sócio-histórica da luta contra a aids conduzida no Brasil no período de 1981-2001. Ela traça a evolução da resposta social à epidemia desde a ocorrência dos primeiros casos diagnosticados até a implementação pelos poderes públicos brasileiros de um programa ambicioso de acesso universal da população afetada pelo vírus aos tratamentos antirretrovirais - quimioterapia combinada antirretroviral e antiprotease. Programa que valeu ao Brasil ser apresentado como um modelo de política antiaids para países em desenvolvimento.

Quando no início do ano de 2009, Sandra Garrido se inscreveu no doutorado sob a orientação de Ligia Vieira da Silva, professora do Instituto de Saúde Coletiva da Universidade Federal da Bahia, com a proposta de trabalhar sobre a política brasileira de luta contra a aids, já existia uma abundante literatura internacional tratando das respostas sociais à epidemia. Diversos trabalhos, notadamente os mais antigos, a respeito dos países do mundo ocidental - Estados Unidos da América, países europeus. Isso porque esses foram os primeiros onde a doença adquiriu visibilidade social de um flagelo, despertando mobilizações sociais e, com isso, promovendo a criação de políticas públicas. Além disso, a proximidade social entre os meios científicos e a população homossexual, à época a mais afetada pela doença, levou muitos pesquisadores das ciências humanas e sociais a se engajarem "cientificamente", estudando os movimentos coletivos que se organizavam e as estratégias de luta que eles implementavam. Mas as questões colocadas pelo desenvolvimento da epidemia fora dos países do chamado "primeiro mundo", fomentaram, por sua vez, estudos que deram uma dimensão verdadeiramente internacional às pesquisas 
sobre "AIDS" nas ciências sociais e políticas - o que, em suma, é o caso apenas de um número limitado de doenças.

Ao familiarizar-se com uma produção científica, rica em diversidade das questões tratadas e ainda heterogêneas em suas abordagens, abrangendo toda a gama de níveis de análise, desde a microssociologia das pesquisas etnográficas até as grandes sínteses internacionais, Sandra Garrido compromete-se a definir o que será o objeto de sua pesquisa. É neste momento que, dado a uma série de seminários em Salvador, a conheci. Convidado pela professora Ligia Maria Vieira da Silva, como parte de um programa de cooperação com o Instituto de Saúde Coletiva, apresento os resultados de várias pesquisas sócio-históricas sobre políticas de saúde, uma das quais, realizada com uma equipe de pesquisadores parisienses, analisa o movimento de luta contra a aids na França desde sua emergência no início dos anos 1980 até os anos 1996, momento da implementação da triterapia. Nesta pesquisa, nós tratamos das relações complicadas - na França - entre as organizações que estruturavam o universo do homossexualismo parisiense e a primeira geração de associações “aids”. Estas, criadas por ex-militantes de grupos políticos da extrema esquerda pós-1968, recusavam uma abordagem homossexual comunitária da luta contra a aids - do tipo que havia se estabelecido nos países anglo-saxônicos -, pois para apoiar todos os doentes, uma causa deve mobilizar aqueles que se sentiam afetados direta ou indiretamente pela epidemia. Acompanhamos, em seguida, a evolução do movimento associativo, seu desenvolvimento ligado à nova visibilidade que os testes de soropositividade deram à epidemia, suas divisões, a diversificação de seus modos de intervenção, a aparição com Act-Up Paris de um pólo ativista radical, a dinâmica de relações interassociativas, colaboração e lutas de concorrência. Nós mostramos que essa evolução mantém relações de interdependência com as iniciativas tomadas pela burocracia da saúde pública e pelos sucessivos governos, notadamente durante a formulação e implementação de uma política de luta contra a aids, cuja viabilidade fundamentou-se em uma aliança entre as instituições de saúde pública, os médicos encarregados dos pacientes e o movimento associativo. Analisamos as consequências tanto nas instituições públicas com a criação de novas estruturas especializadas - agência 
nacional para a pesquisa contra a aids, agência francesa de luta contra a aids que se encarrega da prevenção etc. - quanto nas orientações das associações e na sua institucionalização ligada ao financiamento público, bem como ao pensamento de estado relativo às questões da toxicomania e da homossexualidade. Nas instituições públicas, houve uma relativização da lógica terapêutica baseada na abstinência, até então dominante, em benefício de uma lógica, que privilegiava a "redução de risco" da contaminação. Já nas associações, observou-se a implementação de uma política destinada a fomentar o desenvolvimento de estruturas de socialização para homossexuais, gays e lésbicas, além de proporcionar um quadro legal para o reconhecimento de casais homossexuais.

Sandra Garrido decide então se inspirar na nossa abordagem, e eu aceito com prazer coorientar sua tese - a obtenção de uma bolsa de estudo "sanduíche" lhe permitiu passar um ano na França em nosso laboratório. Assim, ela se diferenciará dos trabalhos que até então abordaram a questão da luta contra a aids no Brasil, focalizados na análise das respostas governamentais à epidemia e limitando o alcance do estudo a um período limitado ou a exemplos de políticas locais. Sandra Garrido almejava aproveitar a política brasileira a longo prazo para relatar suas diferentes fases desde as primeiras ações no estado de São Paulo - quando a doença ainda não tinha sido caracterizada como aids e que nada permitia prever a magnitude que a epidemia tomaria até o lançamento dessa política nacional que colocaria o Brasil na vanguarda da luta contra a aids nos países em desenvolvimento. Para realizar tal projeto, ela se apoia em um importante trabalho empírico, explorarando arquivos e coletando informações orais, da coleta e análise de inúmeros relatórios administrativos, do texto de leis, de "literatura cinza", e também de publicações de todos os tipos artigos de imprensa, textos de associações antiaids. Também entrevistas em profundidade com figuras históricas de militância associativa, de gestores e médicos que desempenharam papéis de liderança nas várias fases da luta contra a aids. Mas este trabalho empírico não é feito cegamente. Ele é guiado por uma problemática aberta que ajuda a enriquecê-lo, sugerindo novos caminhos. Sua perspectiva teórica, de início, a faz desenhar dois grandes princípios de análise. O primeiro interpreta a evolução da 
política de aids como sendo o produto de uma dinâmica social, ou seja, uma dinâmica que resulta da interpenetração das estratégias de agentes que compartilham o objetivo de lutar contra a epidemia, mas que, pertencendo a vários campos sociais - militantes de associações, médicos, membros da gestão, políticos etc. - ocupam posições diferentes e não têm a mesma visão do que deve ser a luta contra a aids, nem os mesmos interesses a defender. O segundo, inspirado pela teoria de campo de Pierre Bourdieu, se propõe a analisar os discursos e as práticas da luta contra a aids como produções de um espaço social específico na interface dos diferentes campos, aos quais pertenciam os agentes envolvidos nessa luta. Sabendo que este espaço é ao mesmo tempo o terreno de colaboração entre esses agentes e de luta de concorrência, na qual o que está em jogo é a definição da (boa) política de luta contra a aids e os meios de sua implementação.

Sandra Garrido se empenha então em reconstruir a gênese de um "espaço aids brasileiro" com suas próprias especificidades e as transformações que ele experimentará ao longo de sua história, colocando tudo na história dos diferentes campos - médico, associativo, burocrático religioso e político - envolvidos, de uma forma ou de outra, por alguns de seus agentes na luta contra a epidemia. Isso para entender quais poderiam ser os interesses próprios de um médico, um voluntário associativo, um político etc., de investir em um dado momento na luta contra a aids. E ela vai fazê-lo de uma forma muito "profissional”. Nada na obra que nos é dada para ler sugere que sua formação universitária não a preparou para esse trabalho, ela se apropriou no próprio momento de sua pesquisa, e de uma forma muito notável das ferramentas conceituais da sociologia, e particularmente as desenvolvidas por Pierre Bourdieu - campo, habitus, capital simbólico, capital social etc. Muitas foram as discussões que tivemos durante a sua estadia no Centro Europeu de Sociologia e Ciência Política, das quais não só mantive a memória do seu entusiasmo e da sua capacidade de reflexão, questionamento, além a sua compreensão dos conceitos à luz dos problemas que encontrava ao analisar seu material.

Mais algumas linhas para apresentar o que eu acho que são as principais características da obra. Sandra Garrido nos mostra as semelhanças 
que a luta contra a aids no Brasil apresenta com o que aconteceu em muitos países. Assim, ela está estruturada, como na maioria dos países ocidentais, por uma aliança - às vezes conflituosa - entre militantes de organizações não governamentais, os médicos e os agentes da gestão de saúde pública envolvidos seja na pesquisa, seja no suporte médico e social dos doentes ou nas campanhas de prevenção e de triagem. Essa aliança tripla está ligada a uma especificidade histórica da epidemia de aids encontrada no Brasil, como em outros lugares, a saber, a existência de uma fase inicial em que a epidemia ainda parece de baixa intensidade, circunscrita a grupos sociais marginais, predispostos à estigmatização, nos quais a doença rapidamente se mostra letal e insensível ao tratamento. Apenas a prevenção pode permitir um controle da epidemia. De fato, nessa fase em que a prevenção é o principal recurso, a colaboração de médicos e das autoridades administrativas com os primeiros militantes associativos, homossexuais na sua maior parte, aparece como uma condição necessária para uma intervenção preventiva direcionada à população mais ameaçada pela epidemia e que, para ser eficaz, deve evitar qualquer forma de estigmatização. Garrido confirma o fato de que essa colaboração está condicionada à existência de formas pré-existentes de organização do meio "gay", como é o caso na cidade de São Paulo, onde a primeira política de luta contra a aids foi iniciada por uma reunião entre um grupo de militantes que lutam pelos direitos dos homossexuais e representantes da Secretaria Estadual de Saúde. O livro também destaca que no Brasil, como na França ou nos EUA, a dinâmica da mobilização associativa evolui em relação às mudanças na representação da epidemia que aparecem com a chegada no mercado dos testes diagnósticos revelando a amplitude da contaminação por HIV e, depois, novamente com a descoberta de métodos eficazes de tratamento.

Mas é o destaque das especificidades da luta contra a aids no Brasil que dá a este livro todo o seu interesse em trazer novos elementos que enriquecem a dimensão comparativa fundamental para qualquer reflexão sociológica. Essas especificidades não refletem as peculiaridades dos movimentos homossexuais e associativos, mas a conjunção própria à história brasileira, entre a ocorrência da epidemia e o desenvolvimento do 
movimento para a reforma sanitária, nascida sob a ditadura militar e que, com o retorno à democracia, será atualizada em uma reorganização do sistema de saúde. Em outras palavras, e isso é o que Sandra Garrido nos mostra, as formas tomadas pela luta contra a aids no Brasil que dependem da relação entre médicos, gestão e associações, serão, em grande medida, determinadas pelas questões da Reforma Sanitária. Por conseguinte, ao contrário da França, por exemplo, observa-se o papel pioneiro da gestão da saúde no nascimento do movimento e a posição dominante durante todo o processo. Nós vemos da mesma forma como a importância das questões políticas relacionadas ao sistema de saúde, desde a sua reorganização, é o que favorece o distanciamento do governo vis-à-vis das diretrizes preconizadas pelo Banco Mundial sobre a proteção da propriedade intelectual de empresas farmacêuticas multinacionais e o que impulsiona a adoção de uma política de acesso universal a tratamentos retrovirais. Assim, se a epidemia não é a causa mais importante da mortalidade no país, os objetivos conferidos à luta contra a aids o fazem um caso exemplar de intervenção, concretizando as ambições da Reforma Sanitária. Este caso é ainda mais exemplar, porque é acompanhado por uma luta internacional contra os trustes farmacêuticos, tendo como consequência uma modificação das regras do jogo estabelecidas pela Organização Mundial do Comércio (OMC). Entendemos nessas condições porque, enquanto que em muitos países, a chegada de tratamentos eficazes ajuda a "normalizar" a luta contra a aids e é acompanhada por uma forte desmobilização do movimento associativo, o desafio do acesso universal ao tratamento, pelo contrário, estimulará o crescimento desse movimento no Brasil.

Um livro que é um marco para qualquer pessoa interessada na luta contra a aids, pela sociologia e pela política de saúde.

\section{Patrice Pinell}

Paris, 3 de maio de 2017. 